\title{
Alteration zone Mapping in the Meiduk and Sar Cheshmeh Porphyry Copper Mining Districts of Iran using Advanced Land Imager (ALI) Satellite Data
}

\author{
Amin Beiranvand Pour*, Mazlan Hashim \\ Geoscience and Digital Earth Centre (Geo-DEC) \\ Research Institute for Sustainability and Environment (RISE) \\ Universiti Teknologi Malaysia (UTM) \\ 81310 UTM Skudai, Johor Bahru, Malaysia \\ *Corresponding author: a.beiranvand@utm.my
}

Commission VI, WG VI/4

KEY WORDS: EO-1; ALI lithological mapping; Hydrothermal alteration mineral; Geological implications

\begin{abstract}
:
This study evaluates the capability of Earth Observing-1 (EO1) Advanced Land Imager (ALI) data for hydrothermal alteration mapping in the Meiduk and Sar Cheshmeh porphyry copper mining districts, SE Iran. Feature-oriented principal components selection, 4/2, 8/9, 5/4 band ratioing were applied to ALI data for enhancing the hydrothermally altered rocks associated with porphyry copper mineralization, lithological units and vegetation. Mixture-tuned matched-filtering (MTMF) was tested to discriminate the hydrothermal alteration areas of porphyry copper mineralization from surrounding environment using the shortwave infrared bands of ALI. Results indicate that the tested methods are able to yield spectral information for identifying vegetation, iron oxide/hydroxide and clay minerals, lithological units and the discrimination of hydrothermally altered rocks from unaltered rocks using ALI data.
\end{abstract}

\section{INTRODUCTION}

Economic geologists can conduct reconnaissance via remote sensing data for exploring porphyry copper, epithermal gold, massive sulfide and uranium mineralization. Multispectral and hyperspectral remote sensing images have been used in geological applications, ranging from a few spectral bands and more than 100 contiguous bands, covering the visible to shortwave infrared regions of the electromagnetic spectrum (Pour and Hashim, 2011, 2013; Pour et al., 2013).

As one of the geological applications of remote sensing, recognizing hydrothermally altered rocks is a common practice in the exploration of epithermal gold, porphyry copper, massive sulfide and uranium deposits (Pour et al., 2014; Kruse et al 2003). The Earth Observing-1 (EO-1) satellite was launched on 21 November of 2000 as part of NASA's New Millennuim Program (NMP) technology path-finding activities to enable more effective (and less costly) hardware and strategies for meeting earth science mission needs in the 21st century. The EO-1 platform includes three the most advanced remote sensing instruments (i) The Advanced Land Imager (ALI); (ii) Hyperion; and (iii) The Linear Etalon Imaging Spectral Array (LEISA) Atmospheric Corrector (LAC). These sensors can be used in a variety of scientific disciplines (Ungar et al., 2003).

The Advanced Land Imager (ALI) sensor was built as archetype for the next production Landsat satellites while the multispectral characteristics were maintained to Enhanced Thematic Mapper Plus (ETM+) sensor on Landsat-7 with a spatial resolution of $30 \mathrm{~m}$ and a swath width of $37 \mathrm{~km}$. ALI has 10 channels spanning the visible and near infrared (VNIR) to shortwave infrared (SWIR) from 0.4 to $2.35 \mu \mathrm{m}$ (one panchromatic band: 0.480-0.690 $\mu \mathrm{m}$; six bands in VNIR (b1: 0.433-0.453 $\mu \mathrm{m}$, b2: 0.450-0.515 $\mu \mathrm{m}$, b3: 0.525-0.605 $\mu \mathrm{m}, \mathrm{b} 4: 0.633-0.690 \mu \mathrm{m}, \mathrm{b} 5$ :
0.775-0.805 $\mu \mathrm{m}, \mathrm{b} 6: 0.845-0.890 \mu \mathrm{m})$; and three bands in SWIR (b7: 1.200-1.300 $\mu \mathrm{m}$, b8: 1.550-1.750 $\mu \mathrm{m}$, b9: 2.080$2.350 \mu \mathrm{m}))$. In the field of geology, VNIR bands $(0.4$ to $1.0 \mu \mathrm{m})$ are especially useful for discriminating among ferric-iron bearing minerals. SWIR bands (1.20 to $2.35 \mu \mathrm{m})$ are sensitive to hydroxyl $(\mathrm{OH})$ minerals that can be found in the alteration zones associated with hydrothermal ore deposits (Ungar et al., 2003).

Porphyry copper deposits are generated by hydrothermal fluid processes that alter the mineralogy and chemical composition of the country rocks. Alteration produces distinctive mineral assemblages with diagnostic spectral absorption features in the visible and near infrared (VNIR) through the shortwave infrared (SWIR) (0.4-2.5 $\mu \mathrm{m})$ and/or the thermal infrared (TIR) (8.0 $14.0 \mu \mathrm{m}$ ) wavelength regions (Pour and Hashim, 2011). Hydrothermal alteration minerals with diagnostic spectral absorption properties in the visible and near infrared through the shortwave length infrared regions can be identified by multispectral and hyperspectral remote sensing data as a tool for the initial stages of porphyry copper and epithermal gold exploration (Di Tommaso and Rubinstein, 2007; Gabr et al., 2010; Kruse et al., 2003; Pour and Hashim, 2014, 2015).

In this study, feature-oriented principal components selection (FPCS), different band ratios and spectral mapping methods were tested on ALI data for mapping lithology, hydrothermal alteration area and vegetation at regional scale. Our image analyses focuses on the Meiduk and Sar Cheshmeh porphyry copper deposits, which are located in the southeastern part of the Urumieh-Dokhtar volcanic belt, SE Iran (Figure 1), where $\mathrm{Cu}$ and $\mathrm{Mo}$ are actively being mined. The main objectives of this research are: (i) to evaluate ALI spectral bands for hydrothermal alteration mapping, (ii) to discriminate lithologically different rock units in study area and (iii) to 
evaluate abilities of the applied image processing methods for exploration of potential zones of porphyry copper mineralization. The achievements of this investigation should have considerable implications for geologists to utilize ALI data for geological purposes.

\section{MATERIALS AND METHODS}

\subsection{Geology of the study area}

Figure 1 shows a simplified geology map of the southeastern segment of the Urumieh-Dokhtar Volcanic Belt. Porphyry copper deposits in this belt are associated with Miocene adakite-like orogenic granitoids which intrude the Eocene volcanic rocks (Pour and Hashim, 2015). In this area, yearly precipitation averages 25 centimeters or less, thus the deposit's exposure is well due to sparse or no vegetation cover.

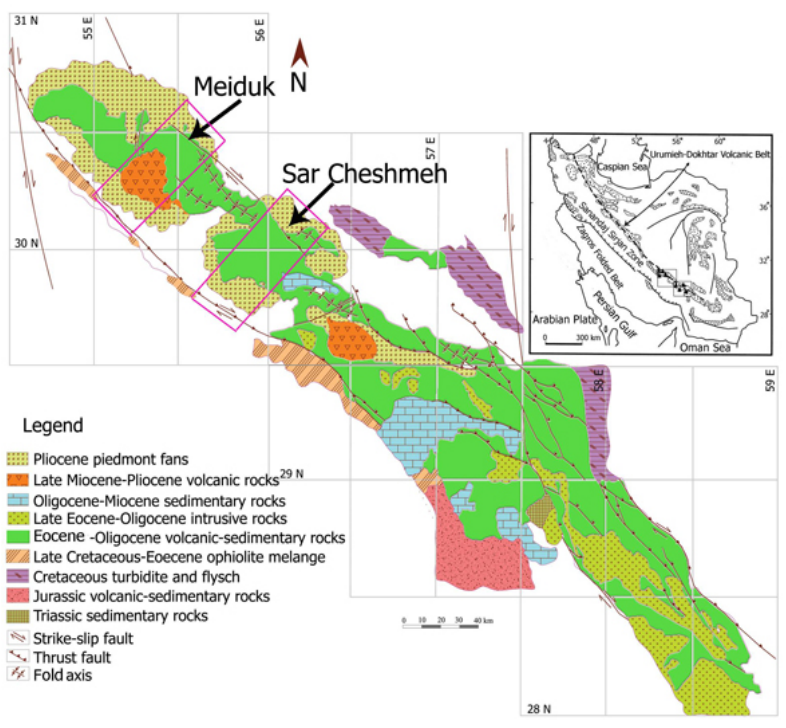

Fig.1. Simplified geology map of southeastern segment of the Urumieh-Dokhtar volcanic Belt (Pour and Hashim, 2015). Study areas are located in rectangles.

\subsection{Satellite remote sensing data and image processing methods}

Two cloud-free level 1B ALI images were obtained through the U.S. Geological Survey Earth Resources Observation System (EROS) Data Center (EDC). The images were pregeoreferenced to UTM zone 40 North projection using the WGS-84 datum.

The datasets used in this study were processed using the ENVI (Environment for Visualizing Images) version 4.8 software package. To correct the atmospheric effects, the Atmospheric CORrection Now (ACORN) software was used to retrieve the surface reflectance. During the atmospheric correction, raw radiance data from imaging spectrometer is re-scaled to reflectance data. Therefore, all spectra are shifted to nearly the same albedo. The resultant spectra can be compared with the reflectance spectra of the laboratory or filed spectra, directly. To evaluate the ALI data the feature-oriented principal components selection (FPCS - Singh and Harrison, 1985), different band ratioing and Mixture Tuned Matched Filtering (MTMF) methods were tested for enhancing the hydrothermally altered rocks associated with porphyry copper mineralization, lithological units and vegetation at regional scale. The principal component analysis (PCA) is a multivariate statistical technique that selects uncorrelated linear combinations (Eigenvector loadings) of variables in such a way that each component successively extracted linear combination and has a smaller variance (Singh and Harrison, 1985). Mixture Tuned Matched Filtering (MTMF) method is a combination of the best parts of the linear spectral mixing model and the statistical matched filter model while avoiding the drawbacks of each parent method (Boardman, 1998; Kruse et al 2003).

\section{RESULTS AND DISCUSSION}

\subsection{Principal component analysis (PCA)}

Feature-oriented principal components selection (FPCS) method was tested to ALI data for selecting particular principal components images that characterize the unique absorption features or minerals based on observation of the eigenvector matrix of a multispectral image dataset. Two combinations of the ALI bands are selected for this purpose. Bands 1, 2, 4 and 5 are used for enhancing iron oxide minerals and bands $1,7,8$ and 9 to identify clay minerals. Iron oxide/hydroxide minerals exhibit spectral absorption features in the visible to middle infrared from 0.4 to $1.1 \mu \mathrm{m}$ of the electromagnetic spectrum (Hunt and Ashley 1979). Landsat bands 1 (the equivalent to ALI band 2) and 3 (the equivalent to ALI band 4) have been used to map limonite-rich rocks containing limo $\neg$ nite, goethite and hematite, which are a potential indicator of supergene deposits. Hence, bands $2(0.450-0.515 \mu \mathrm{m})$ and 4 (0. 633-0.690 $\mu \mathrm{m})$ of ALI contain typical features that can be used to map iron oxide/hydroxide minerals. Clay minerals have absorption features from 2.1 to $2.4 \mu \mathrm{m}$ (band 9 of ALI) and reflectance from 1.55 to $1.75 \mu \mathrm{m}$ (band 8 of ALI ) that correspond with bands 7 and 5 of ETM+, respectively. It is evident that bands 2, 4, 8 and 9 of ALI can be used for hydrothermal alteration mapping. Statistical factors are calculated for each dataset, and covariance eigenvector values are examined. Tables 1, 2, 3 and 4 show the transformation of the PCs for Meiduk and Sar Cheshmeh scenes.

Table 1: Covariance eigenvector values of the principal components (PCs) of the first dataset (1, 2, 4 and 5 bands of ALI) for iron oxide minerals and vegetation, Meiduk scene.

$\begin{array}{lllll}\text { Input bands } & \text { Band 1 } & \text { Band 2 } & \text { Band 4 } & \text { Band 5 } \\ \text { PC1 } & 0.492 & 0.499 & 0.506 & 0.520 \\ \text { PC2 } & 0.593 & 0.382 & -0.333 & -0.581 \\ \text { PC3 } & 0.343 & -0.750 & -0.710 & 0.625 \\ \text { PC4 } & 0.536 & -0.202 & 0.358 & -0.140\end{array}$


Table 2: Covariance eigenvector values of the principal components (PCs) of the first dataset (1, 2, 4 and 5 bands of ALI) for iron oxide minerals and vegetation, Sar Cheshmeh scene.

$\begin{array}{llccc}\text { Input bands } & \text { Band 1 } & \text { Band 2 } & \text { Band 4 } & \text { Band 5 } \\ \text { PC1 } & 0.492 & 0.497 & 0.506 & 0.505 \\ \text { PC2 } & 0.584 & 0.392 & -0.321 & -0.579 \\ \text { PC3 } & 0.300 & -0.763 & -0.748 & 0.633 \\ \text { PC4 } & 0.572 & -0.124 & 0.285 & -0.091\end{array}$

Table 3: Covariance eigenvector values of the principal components (PCs) of the second dataset (1, 7, 8 and 9 bands of ALI) for hydroxyl minerals, Meiduk scene.

$\begin{array}{ccccr}\text { Input bands } & \text { Band 1 } & \text { Band 7 } & \text { Band 8 } & \text { Band 9 } \\ \text { PC1 } & 0.470 & 0.509 & 0.12 & 0.507 \\ \text { PC2 } & 0.870 & -0.132 & -0.305 & -0.363 \\ \text { PC3 } & 0.147 & -0.725 & -0.023 & 0.444 \\ \text { PC4 } & 0.035 & -0.397 & 0.802 & -0.642\end{array}$

Table 4: Covariance eigenvector values of the principal components (PCs) of the second dataset (1, 7, 8 and 9 bands of ALI) for hydroxyl minerals, Sar Cheshmeh scene.

$\begin{array}{lrrrr}\text { Input bands } & \text { Band 1 } & \text { Band 7 } & \text { Band 8 } & \text { Band 9 } \\ \text { PC1 } & 0.475 & 0.505 & 0.510 & 0.509 \\ \text { PC2 } & 0.870 & -0.151 & -0.314 & -0.579 \\ \text { PC3 } & 0.120 & -0.740 & -0.036 & 0.430 \\ \text { PC4 } & 0.044 & -0.415 & 0.800 & -0.660\end{array}$

After analysing the magnitude and sign of the covariance eigenvector values of the PCs for the first dataset (Bands 1, 2, 4 and 5), it has been observed that iron oxides can be distinguished as dark pixels in PC3 of both Meiduk and Sar Cheshmeh images because of the negative contribution from band 4 (reflective band) $(-0.710)$ and $(-0.748)$ and negative weighting of band 2 (absorption band) $(-0.750)$ and $(-0.763)$ for the Meiduk and Sar Cheshmeh images, respectively (Tables 1 and 2). If the eigenvector loadings are positive in the reflective band of a mineral the image tone will be bright, and if they are negative, the image tone will be dark for the enhanced target mineral. So, the PC3 image shows iron oxide minerals as dark pixels that appear around the known and mined porphyry copper deposits in the study areas Figure 2 shows iron oxide minerals associated with known copper deposits in Sar Cheshnmeh mining district. It seems that bands 4 (0.633-0.69 $\mu \mathrm{m})$ and $5(0.775-0.805 \mu \mathrm{m})$ of ALI have distinctive characteristics that can be utilized to discriminate iron oxide/hydroxide minerals from vegetation. Therefore, vegetation manifests as bright pixels in PC3 image (Figure 2) due to the positive contribution from band 5 (0.625) and (0.633) for the Meiduk and Sar Cheshmeh images, respectively (Tables 1 and 2).

Considering the magnitude and sign of the eigenvector loadings of the PCs for the second dataset (Bands 1, 7, 8 and 9), it is evident that the PC4 image manifests desired information related to $\mathrm{Al}(\mathrm{OH})$-bearing (clay) minerals as bright pixels. Eigenvector loadings of PC4 in band 8 (reflective band) are (0.802) and (0.800), while in band 9 (absorption band) are $(-0.642)$ and $(-0.660)$ for the Meiduk and Sar Cheshmeh images, respectively (Tables 3 and 4). Thus, clay minerals (hydrothermally altered rocks) around the known and mined porphyry copper deposits appear as bright pixels in PC4 image in ALI scenes. Using geology maps as the reference, it seems that a few bright pixel areas are associated with sedimentary rocks in the north (Cretaceous flysch and Palegene flysch) and west (Palegene flysch) of the Meiduk image (Figure 3). Sedimentary rocks such as mudstone, shale, claystone and litharenite sandstones contain large amounts of detrital clays such as montmorillonite, illite and kaolinite.

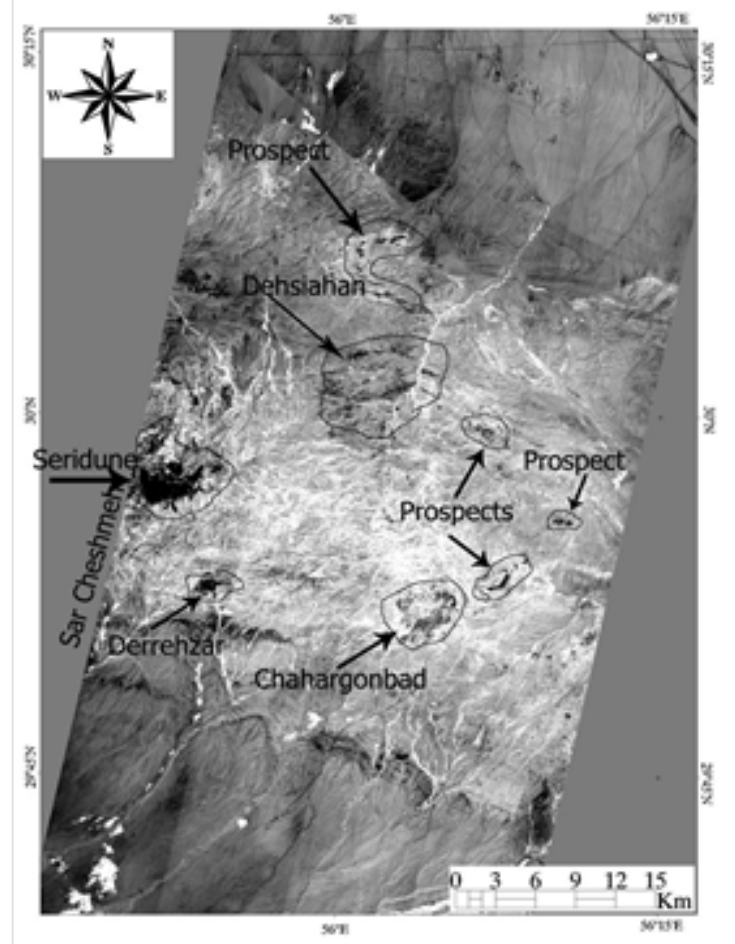

Fig. 2. PC3 image shows iron oxide minerals as dark pixels that appear around the known and mined porphyry copper deposits in the Sar Cheshmeh ALI scene.

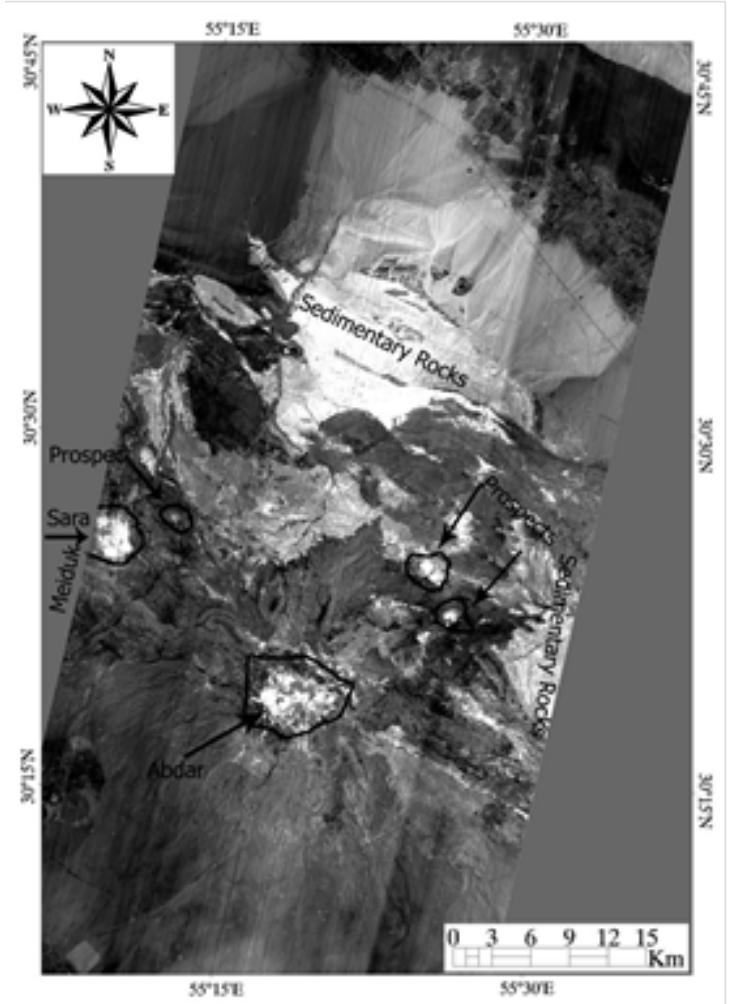

Fig. 3. PC4 image shows clay minerals (hydrothermally altered rocks) around the known and mined porphyry copper deposits as bright pixels in the Meiduk ALI scene. 


\subsection{Band ratioing}

As the first step towards the identification of hydrothermal alteration minerals using ALI data, band ratios were created based on laboratory spectra of the minerals related with hydrothermal alteration. Mapping iron oxides is carried out using bands 2 and 4 of ALI because iron oxide/hydroxide minerals such as hematite, jarosite and limonite have high reflectance in the spectral region 0.63 to $0.69 \mu \mathrm{m}$ (the equivalent to ETM+ band 3) and high absorption in the spectral region 0.45 to $0.52 \mu \mathrm{m}$. The identification of minerals needs bands 8 and 9 of ALI because of their high reflectance in the range of 1.55 to $1.75 \mu \mathrm{m}$ and high absorption in 2.08 to 2.35 $\mu \mathrm{m}$. Based on the FPCS results, bands 4 and 5 of ALI can be used to identify vegetation. Accordingly, a false colour composite of band ratios (4/2, 8/9, 5/4 in RGB) was developed. This band ratio composite allows for the identification of altered rocks, lithological units and vegetation. The alteration minerals (hydrothermally altered rocks) are outlined in the images where they appear as yellow color around known and mined porphyry copper deposits (Figure 4, Meiduk region). The locations of the known and mined copper deposits and identified prospects are highlighted. Vegetation is shown in blue, and lithological units are identifiable in terms of a variety of colours in ALI scenes.

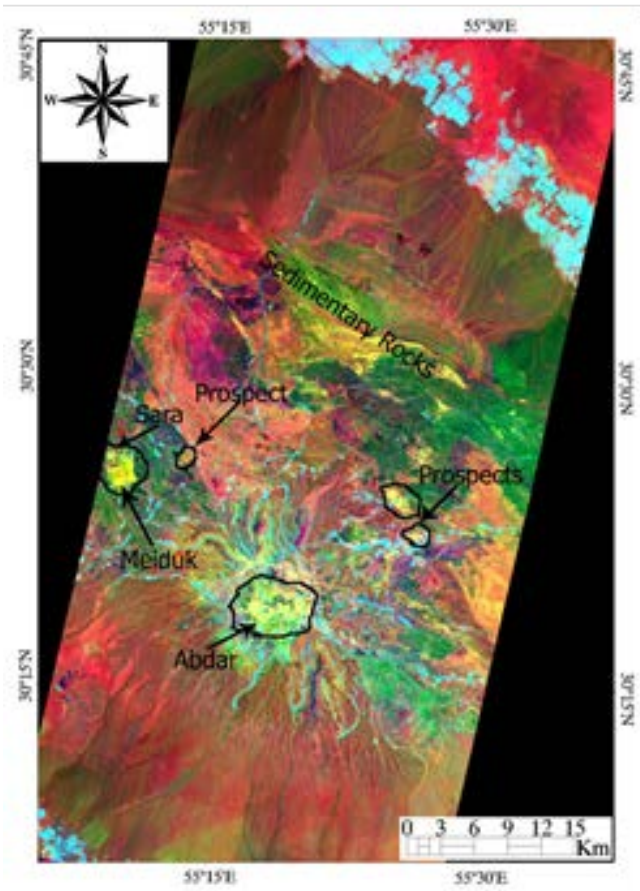

Fig. 4. ALI band ratio image of 4/2, 8/9, 5/4 in RGB shows hydrothermally altered rocks as yellow color around known and mined porphyry copper deposits.

\subsection{Mixture Tuned Matched Filtering (MTMF)}

Spectral mapping methods were tested with two selected spatial subset of ALI scenes covering both the Meiduk and Sar Cheshmeh mining districts for regional scale mapping. Automated spectral Hourglass was applied to the SWIR bands of ALI to extract reference spectra directly from the image. Mixture-tuned matched-filtering (MTMF) was performed to discriminate hydrothermally altered rocks from unaltered rocks at regional scale. Hydrothermally altered rocks associated with the known and mined porphyry copper deposits and identified prospects are well recognized from surrounding areas at regional scale. In this study, MTMF visual results are shown in Figure 5 (a-b). Bright pixels show hydrothermally altered rocks associated with the known and mined copper deposits and identified prospects in the ALI images.
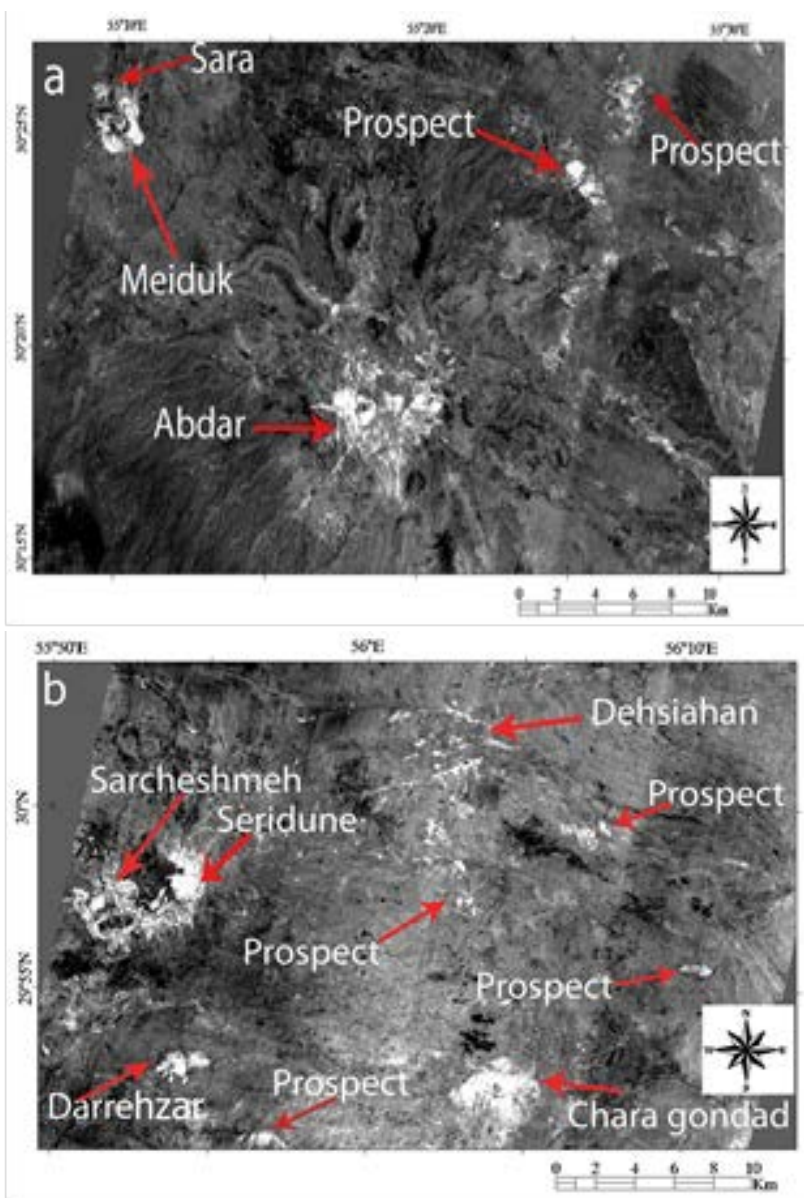

Fig.5. MTMF visual results derived from SWIR bands of ALI subscene. (a): Meiduk ALI sub-scene and (b): Sar Cheshmeh ALI sub-scene.

\section{CONCLUSIONS}

This study evaluates ALI data to extract geologic information for hydrothermal alteration and lithological mapping using some selected image processing methods. Two porphyry copper mining districts in southeastern segment of the UrumiehDokhtar Volcanic Belt, SE Iran, namely the Meiduk and Sar Cheshmeh have been selected as case studies. FPCS and band ratio methods have yielded spectral information for identifying iron oxide/hydroxide, clay minerals and lithological units using ALI data at regional scale. MTMF is useful in the differentiation of hydrothermally altered rocks associated with the known and mined porphyry copper deposits from unaltered rocks using the SWIR bands of ALI. It is concluded that the extraction spectral information from ALI data can be used for lithological mapping and the detection of hydrothermal alteration minerals associated with porphyry copper and epithermal gold mineralization at regional scale. 


\section{Acknowledgment}

This study was conducted as a part of TRGS grant (Vote no: R.J130000.7809.4L837), Ministry of Higher Education (MOHE) Malaysia. We are thankful to the Universiti Teknologi Malaysia for providing the facilities for this investigation.

\section{References}

Boardman, J. W. 1998. Leveraging the high dimensionality of AVIRIS data for improved sub-pixel target unmixing and rejection of false positives: mixture tuned matched filtering, in: Summaries of the Seventh Annual JPL Airborne Geoscience Workshop, Pasadena, CA, p. 55.

Di Tommaso, I. and Rubinstein, N. 2007. Hydrothermal alteration mapping using ASTER data in the Infiernillo porphyry deposit, Argentina. Ore Geology Reviews, 32, 275290.

Gabr, S., Ghulam, A. and Kusky, T. 2010. Detecting areas of high-potential gold mineralization using ASTER data. Ore Geology Reviews, 38, 59-69.

Kruse, F.A., J.W., Bordman, J.F. Huntington, 2003. Comparison of airborne hyperspectral data and EO-1 Hyperion for mineral mapping. IEEE Transa.Geosci.Remote Sensing, 41(6), 1388-1400.

Pour, A.B Hashim, M., 2011. Application of Spaceborne Thermal Emission and Reflection Radiometer (ASTER) data in geological mapping, Intern.J. Physical Sciences, vol.6 (33), pp.7657-7668.

Pour, A.B Hashim, M., 2013. Fusing ASTER, ALI and Hyperion data for enhanced mineral mapping. Intern.J. Image and Data Fusion, 4(2),126-145.

Pour, A.B., M. Hashim and J.van Genderen, 2013. Detection of hydrothermal alteration zones in a tropical region using satellite remote sensing data: Bau gold field, Sarawak, Malaysia. Ore Geo. Reviews, 54, 181-196.

Pour, A.B., M. Hashim, M, Marghany. M, 2014. Exploration of gold mineralization in a tropical region using Earth Observing-1 (EO1) and JERS-1 SAR data: a case study from Bau gold field, Sarawak, Malaysia. Arab. J. Geosciences, 7, 2393-2406.

Pour, A.B., M. Hashim, 2015. "Hydrothermal alteration mapping from Landsat-8 data, Sar Cheshmeh copper mining district, south-eastern Islamic Republic of Iran, J.Taibah Unive. Science, 9, 155-166.

Singh, A., A. Harrison, 1985. "Standardized principal components,” Intern.J. Remote Sensing, vol.6, pp.883-896.,

Ungar, S.G., J.S., Pearlman, J.A., Mendenhall, 2003. Overview of the Earth Observing One (EO-1) Mission. IEEE Transa.Geosci.Remote Sensing, 41(6), pp. 1149-1159. 